\title{
Improvements to Female Autonomy and Household Decision-Making Power from an Intervention Targeting Improved Food Security: A Gender-Based Analysis of the Rajasthan Nutrition Project
}

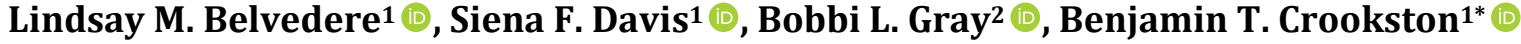 \\ ${ }^{1}$ Department of Public Health, Brigham Young University, Provo, UT, USA \\ ${ }^{2}$ Grameen Foundation, Washington, USA \\ Email: *benjamin_crookston@byu.edu
}

How to cite this paper: Belvedere, L.M., Davis, S.F., Gray, B.L. and Crookston, B.T. (2021) Improvements to Female Autonomy and Household Decision-Making Power from an Intervention Targeting Improved Food Security: A Gender-Based Analysis of the Rajasthan Nutrition Project. Health, 13, 188-203.

https://doi.org/10.4236/health.2021.132017

Received: January 12, 2021

Accepted: February 23, 2021

Published: February 26, 2021

Copyright $\odot 2021$ by author(s) and Scientific Research Publishing Inc. This work is licensed under the Creative Commons Attribution International License (CC BY 4.0).

http://creativecommons.org/licenses/by/4.0/

\begin{abstract}
In India, women and children continue to experience food insecurity. The purpose of this study is to evaluate whether the Rajasthan Nutrition Project (RNP) led to changes in 1) dietary habits and nutrition, and 2) indicators of gender equality, female autonomy, and empowerment. This study surveyed women belonging to self-help groups who were pregnant or who had young children. Over the course of the intervention, significant improvements were seen in the following indicators: breastfeeding within one hour of birth, exclusively breastfeeding for the first six months, food insecurity of children and mothers, household decision-making, communication, mobility, and domestic violence. These findings suggest that the RNP is a promising intervention for improving nutrition and female autonomy in Rajasthan, India. Additional research is needed to determine if the RNP would be equally as effective in other regions of India, or in populations outside of India.
\end{abstract}

\section{Keywords}

India, Rajasthan, Female Autonomy, Food Security, Maternal and Child Health

\section{Introduction}

As of 2019, India ranked $102^{\text {nd }}$ of 133 countries in the Global Hunger Index study of food insecurity [1]. The World Food Programme estimates that $25 \%$ of the world's undernourished population lives in India [2]. Due to socio-cultural 
barriers, women and girls form much of the Indian population lacking food and nutrition security [3]. Food allocation at the household level in South Asia is often determined by relative differences in household members' income, bargaining power, food behaviors, social status, and interpersonal relationships [4], each of which results in females being disadvantaged and experiencing food insecurity.

Research shows that there is also an association between female empowerment, household decision-making power and autonomy, and nutritional status of a mother and her children [5] [6] [7] [8] [9]. Mothers that lack decision-making power/autonomy have an increased risk of their children being stunted [6] [9] [10]. In addition, an association has been seen between female mobility, paid labor and control over income, assets, and resources (financial autonomy), and the nutritional status of both a mother and her children [6]. Specifically, a study from Andhra Pradesh, India found that women with higher autonomy, which included greater access to money and freedom of mobility, were significantly less likely to have a malnourished child [11]. Another study from India found mother's physical and financial autonomy to be significantly associated with child nutrition outcomes, with more autonomy resulting in better nutrition [9]. In general, women in South Asia have lower empowerment status and less decision-making power than women in Sub-Saharan Africa [12].

Rajasthan is one of India's poorest states [13]. Here, women face poor health outcomes and increased restraints due to their gender, often at levels worse than the national average. In Rajasthan, women's empowerment status falls below the national average at 0.4 , compared to the national average of 0.5 (score from the Gender Empowerment Index, with 0 being the worst score and 1 being the best) [14]. Thirty-nine percent of children under five in Rajasthan are stunted, and $46 \%$ of women in the state suffer from anemia [15]. Additionally, only $25 \%$ of married women make decisions about their own healthcare and only $35 \%$ of women participate in the workforce [14]. The child sex ratio in Rajasthan is one of the nation's lowest, with only 888 girls for every 1000 boys [16].

The Rajasthan Nutrition Project (RNP) was designed to address the high prevalence of undernutrition and the low empowerment status of women and girls in Rajasthan. Building on existing women's self-help groups (SHGs) that seek to improve the livelihoods of women, the project sought to provide vital health and nutrition knowledge, increase budgeting and planning skills, improve gender awareness and linkages to nutrition-related services, and advocate for improved health service delivery. The goals of the project were threefold: 1) To improve knowledge, behaviors, and access to local nutrition-related services for women, adolescent girls, and young children; 2) To facilitate dialogue that will lead to increased women's empowerment and more gender-equitable resource management and food distribution within the household; and 3) To improve women's financial literacy, resource management ability, and skills related to planning for better household nutrition.

The present paper seeks to evaluate changes to dietary habits and nutrition 
resulting from the RNP. In addition, this paper will determine whether the RNP led to changes in indicators of gender equality, female autonomy, and empowerment, such as social norms, intra-household decision-making dynamics, female mobility, and domestic violence.

\section{Methods}

\subsection{The Intervention}

In order to meet the goals of the RNP, five strategies were utilized, each of which built upon existing SHGs in Rajasthan's southern districts of Sirohi and Banswara. The five strategies are as follows: 1) Community nutrition advocates (CNAs) and nutrition education; 2) Agricultural extension support; 3) Gender dialogues; 4) Linkages to nutrition and health services; and 5) Savings and income generation. Each of these strategies is outlined in further detail in Figure 1. In total, the RNP reached 8131 SHG members, and trained and engaged 1280 CNAs.

\subsection{Survey Study Design, Procedure, and Sample}

This study consisted of a pre-and post-survey of females who were either pregnant or had a child under the age of two. The baseline assessment was conducted from May to June 2015 with a sample of 403 women that belonged to the SHGs in the districts of Banswara and Sirohi in Rajasthan (see Figure 2). A simple representative random sample was applied and stratified to ensure that at least

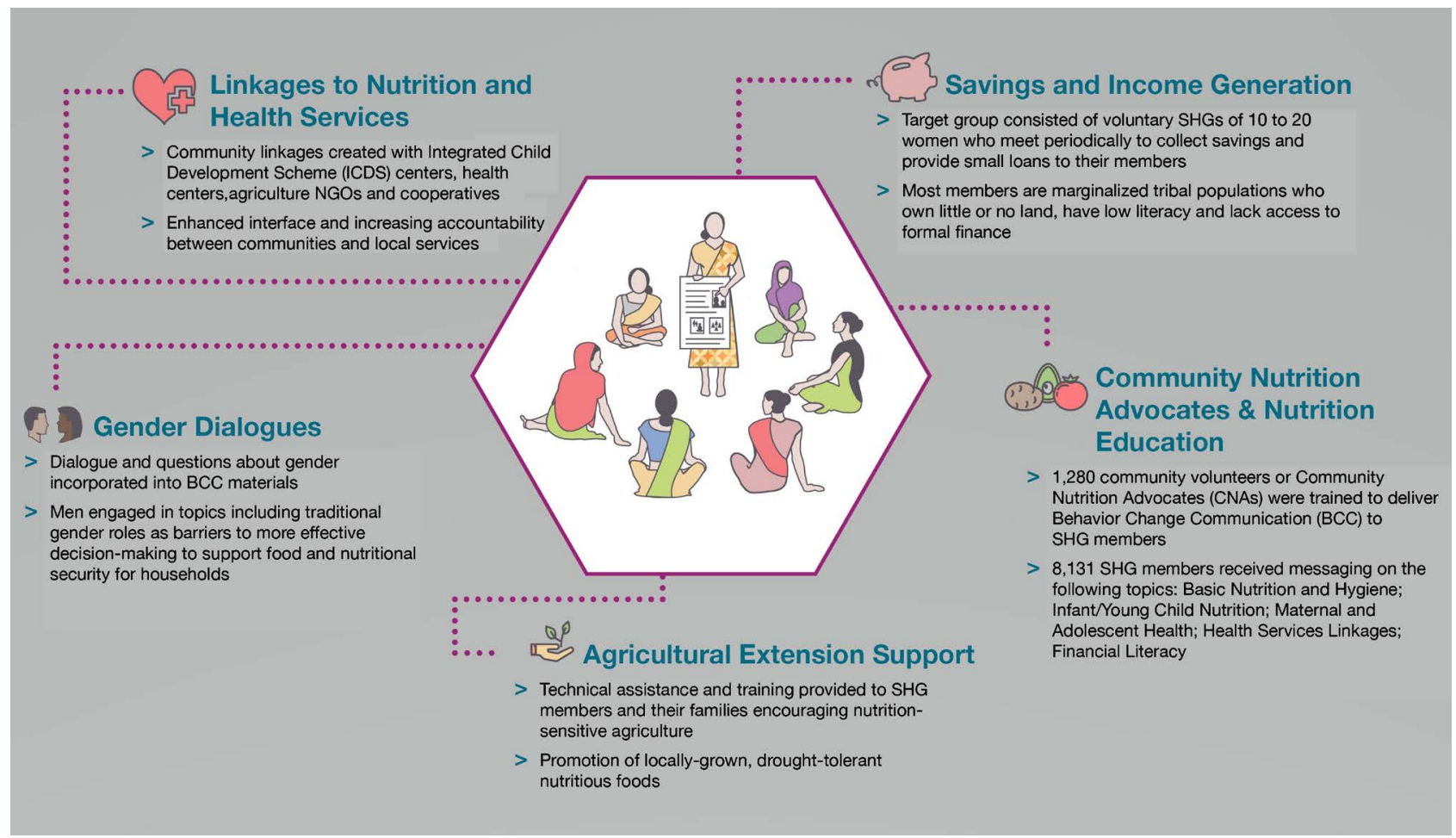

Figure 1. Key strategies of the Rajasthan Nutrition Project (RNP). 


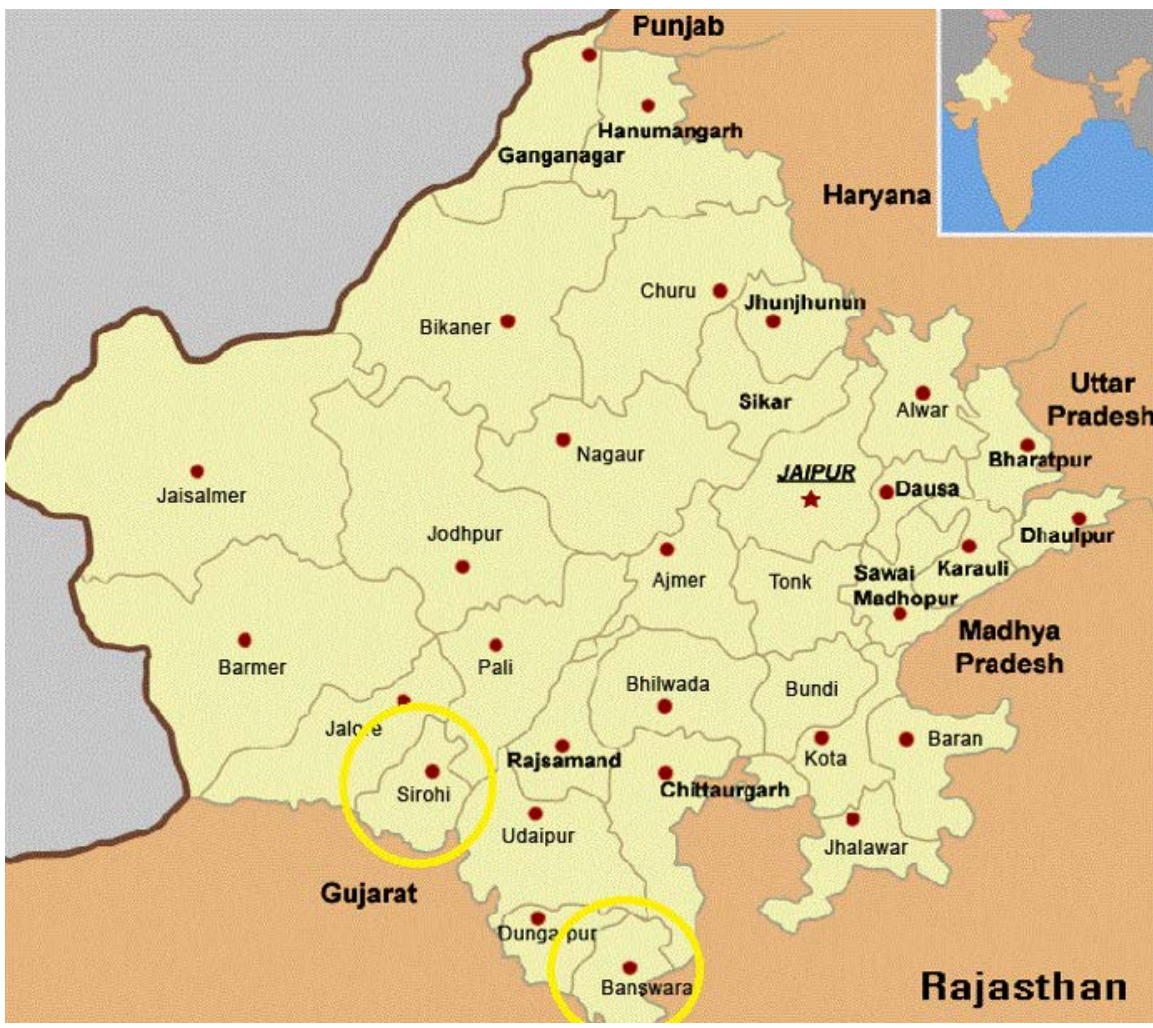

Figure 2. Map of Rajasthan showing study areas.

$20 \%$ of the sample was currently pregnant. Pregnant women and women who could be lactating were targeted for the survey in order to detect changes in key variables related to breastfeeding and infant/child feeding. Figure 3 provides additional details about the selection process for study participants. The districts of Banswara and Sirohi in Rajasthan were chosen as the study areas based on the locations of the project's two implementing partners, Vaagdhara and Pradan.

The endline assessment was conducted from March-April 2017 with 470 women participating. Of those participants, 409 were members of the SHG and 61 were CNAs; $82 \%$ of the samples at endline were also participants at baseline. When an original participant was unable to participate in the endline assessment, they were substituted with a woman who fit the criteria set at baseline, meaning she had to be a mother with a child less than 2 years of age or be pregnant. When possible, the new participant was randomly selected from the same group from which the original respondent came.

The present study is part of a broader project that also includes a qualitative assessment of the RNP and an analysis of additional quantitative measures. These results are not presented in the present study, but are available in Gray et al. [17].

\subsection{Survey Measurement}

Respondents answered questions about demographics, including age, number of years with the SHGs, religion, caste/tribe, marital status, and number, age, and 


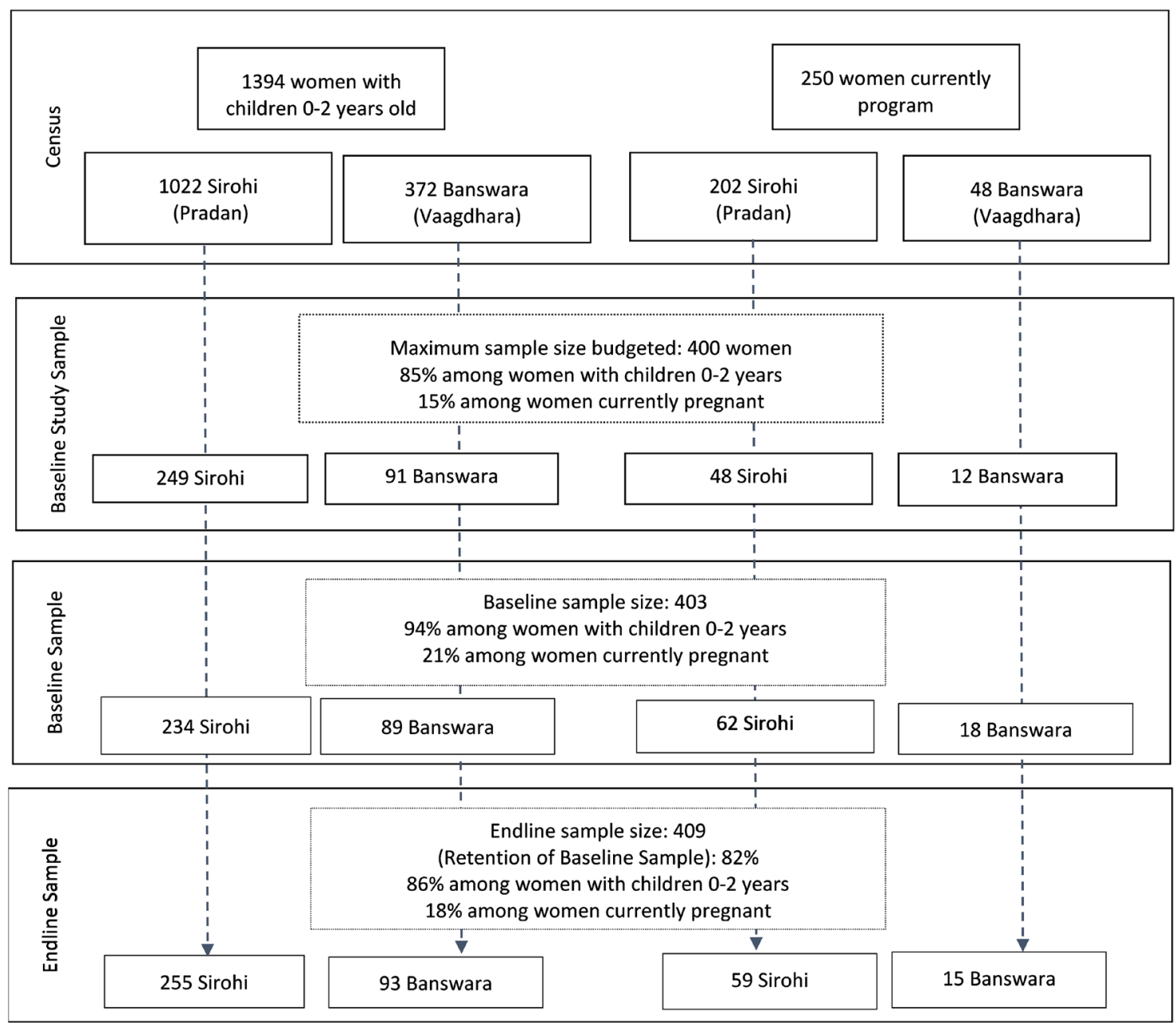

Figure 3. Study sample frame.

gender of children. Household poverty level was assessed with the India Progress out of Poverty Index (PPI) Scorecard developed by the Grameen Foundation [18] and a set of health indicators previously tested for use with microfinance institutions [19]. These indicators include measures of food security, a coping strategies index [20], a dietary diversity index [21], nutrition, sanitation and safe water, curative care, household decision-making, use of Integrated Child Development Scheme (ICDS) services, and breastfeeding and infant/child feeding. Questions were also asked about social norms, mobility, and attitudes towards and experiences with domestic violence. The target values used in this study were those outlined in the National Family and Health Survey (NFHS-4) [22].

\subsection{Statistical Analysis}

Statistical tests were run in SAS (Statistical Analysis Software) 9.4 to obtain frequencies, percentages, and means for demographic questions and to compare key variables of interest to other variables using t-tests and chi-square tests.

The present paper specifically assessed indicators related to nutrition outcomes and gender equality and empowerment, including those related to social 
norms, household decision-making, female mobility, and domestic violence, among others.

\section{Results}

The average age of endline participants was 29 years old (Table 1). Similar to baseline, the majority of the endline sample were Hindu (91.1\%), tribal (91.5\%), and married (97.7\%). Eighty-six percent of participants had a child less than two years of age, and $18.1 \%$ of participants were pregnant at the time of the survey. There was an average of 3 children per mother (1.70 girls and 1.46 boys per mother on average).

All nutrition-related targets of the RNP were met or exceeded over the course of the intervention (Table 2). Notably, the percentage of babies who were breastfed within one hour of birth, the percentage of mothers who were considered food secure, and the percentage of children with diarrhea that utilized oral

Table 1. Demographics.

\begin{tabular}{|c|c|c|c|c|}
\hline \multirow{2}{*}{ Variable } & \multicolumn{2}{|c|}{ Baseline } & \multicolumn{2}{|c|}{ Endline } \\
\hline & $\%$ & Mean & $\%$ & Mean \\
\hline Age & - & 27 & - & 29 \\
\hline Years with SHG & - & 2.4 & - & $1.91(4.5)^{\star}$ \\
\hline \multicolumn{5}{|l|}{ Religion } \\
\hline Hindu & 99.75 & - & 91.10 & - \\
\hline Muslim & 0.25 & - & 0.40 & - \\
\hline Christian & - & - & 8.50 & - \\
\hline \multicolumn{5}{|l|}{ Caste or Tribe } \\
\hline Caste & 9.18 & - & 8.10 & - \\
\hline Tribe & 90.82 & - & 91.50 & - \\
\hline No Caste/Tribe & - & - & 0.40 & - \\
\hline \multicolumn{5}{|l|}{ Marital Status } \\
\hline Single & 1.49 & - & 0.90 & - \\
\hline Married & 96.53 & - & 97.70 & - \\
\hline Separated/Divorced & 0.25 & - & - & - \\
\hline Remarried & 1.74 & - & - & - \\
\hline Widow & - & - & 1.40 & - \\
\hline Children $<2$ years old & 94.43 & - & 86.00 & - \\
\hline Number of children & - & 3.21 & - & 3.16 \\
\hline Number of Girls & - & 1.72 & - & 1.70 \\
\hline Number of Boys & - & 1.55 & - & 1.46 \\
\hline Age of Youngest Child & - & 1.09 & - & 1.02 \\
\hline Pregnancy at Time of Survey & 21.09 & - & 18.10 & - \\
\hline
\end{tabular}

${ }^{*}$ It is believed that respondents interpreted this question as length of time participating in the health projects and not in a SHG. Therefore, the majority of respondents used 2015 as the reference point (the year RNP began) instead of the year they mentioned at baseline. If the year respondents mentioned at baseline were instead used as a reference point, the average length of membership in the SHG would be approximately 4.5 years. 
Table 2. RNP targets, baseline and endline values.

\begin{tabular}{lcc}
\hline \multicolumn{1}{c}{ Variable } & Baseline \% & Endline \% \\
\hline Breastfed within 1 hour of birth & 47.1 & $82.7^{\star}$ \\
Exclusively breastfed for first 6 months & 27.1 & $36.2^{\star}$ \\
Had a child with diarrhea who used ORS & 34.1 & $84.2^{\star}$ \\
Food secure & 21.1 & $52.6^{*}$ \\
Utilized ICDS services in the last 12 months & 60.6 & $92.7^{\star}$ \\
\hline
\end{tabular}

*Indicates statistically significant at $\mathrm{p}<0.05$.

Table 3. Poverty and food security status.

\begin{tabular}{lcc}
\hline \multicolumn{1}{c}{ Variable } & Baseline $\%$ & Endline $\%$ \\
\hline Live below IPL* $\$ 1.25 /$ day & 44.7 & 53.8 \\
Live below IPL* $\$ 2.50$ /day & 82.4 & 85.5 \\
Live below National Poverty Line & 36.7 & 45.7 \\
Child Food Security & & \\
Secure & 23.33 & $52.80^{* *}$ \\
Insecure & 76.67 & 47.20 \\
& & \\
Female Head of Household Food Security & & \\
Secure & 21.09 & $52.60^{* *}$ \\
Insecure & 78.91 & 47.40 \\
\hline
\end{tabular}

${ }^{\star} \mathrm{IPL}=$ International Poverty Line. ${ }^{* *}$ Indicates statistically significant at $\mathrm{p}<0.05$.

rehydration salts (ORS) approximately doubled over the course of the intervention.

Table 3 shows changes to poverty and food security status from baseline to endline. Notably, the percentage of children who were considered food secure increased from $23.3 \%$ to $52.8 \%$, and the percentage of female heads of households who were food secure increased from $21.1 \%$ to $52.6 \%$.

Significant improvements related to household decision-making, communication, and mobility were seen as a result of the RNP (Table 4). Decisions about food purchases when both the husband and wife made decisions together increased from $24.8 \%$ to $48.7 \%$. At the same time, decisions about food purchases made only by the wife decreased from $19.6 \%$ to $8.8 \%$, and those made only by the husband decreased from $36.7 \%$ to $18.3 \%$. Each of these changes was statistically significant.

Women's decision-making power in relation to how much food to serve to family members also increased, with the wife making the decision alone increasing from $40.5 \%$ to $66.3 \%$, and both spouses making the decision together increasing from $11.7 \%$ to $18.8 \%$. Additionally, the proportion of husbands making the sole decision about how much food to serve to family members decreased from $30.8 \%$ to $3.2 \%$. Each of these changes was statistically significant. 
Table 4. Household decision-making, communication and mobility.

\begin{tabular}{|c|c|c|}
\hline Variable & Baseline \% & Endline \% \\
\hline \multicolumn{3}{|l|}{ Decisions about food purchases } \\
\hline Wife decision & 19.6 & $8.8^{*}$ \\
\hline Husband decision & 36.7 & $18.3^{*}$ \\
\hline Both & 24.8 & $48.7^{*}$ \\
\hline Someone else & 18.6 & $24.2^{*}$ \\
\hline \multicolumn{3}{|l|}{ Decisions about how much food to serve to family members } \\
\hline Wife decision & 40.5 & $66.3^{*}$ \\
\hline Husband decision & 30.8 & $3.2^{*}$ \\
\hline Both & 11.7 & $18.8^{*}$ \\
\hline Someone else & 17.1 & $11.1^{*}$ \\
\hline \multicolumn{3}{|l|}{ Decision on how money is spent } \\
\hline Wife decision & 5.2 & $14.9^{*}$ \\
\hline Husband decision & 71.2 & $15.9^{*}$ \\
\hline Both & 23.6 & $51.1^{*}$ \\
\hline Someone else & 0.0 & $18.1^{*}$ \\
\hline \multicolumn{3}{|l|}{ Decision on whether she seeks healthcare for herself } \\
\hline Wife decision & 3.5 & $8.6^{*}$ \\
\hline Husband decision & 69.5 & $28.4^{*}$ \\
\hline Both & 27.1 & $55.3^{*}$ \\
\hline Someone else & 0.0 & $7.7^{*}$ \\
\hline \multicolumn{3}{|l|}{ Decision on whether she can visit family or friends } \\
\hline Wife decision & 4.2 & $10.0^{*}$ \\
\hline Husband decision & 63.8 & $25.2^{*}$ \\
\hline Both & 32.0 & $51.6^{*}$ \\
\hline Someone else & 0.0 & $13.0^{*}$ \\
\hline \multicolumn{3}{|l|}{ Have unrestricted access to income } \\
\hline Yes & 69.4 & 70.9 \\
\hline Spoke to husband in past 6 months regarding food needs & 71.2 & $78.5^{*}$ \\
\hline Spend money most of the time without discussing with husband first & 27.5 & 32.3 \\
\hline \multicolumn{3}{|l|}{ Mobility } \\
\hline Can go to market alone & 28.3 & $73.1^{*}$ \\
\hline Can go to health facility alone & 23.3 & $62.1^{*}$ \\
\hline Can visit friends or family within the village alone & 37.7 & $62.8^{*}$ \\
\hline Can visit friends or family outside of the village alone & 11.9 & $40.1^{*}$ \\
\hline
\end{tabular}

${ }^{*}$ Indicates statistically significant at $\mathrm{p}<0.05$.

Female decision making power also increased in relation to how money is spent (wife alone from 5.2\% to $14.9 \%$; both spouses from $23.6 \%$ to $51.1 \%$; husband alone from $71.2 \%$ to $15.9 \%$ ), whether or not she seeks health care for her- 
self (wife alone from $3.5 \%$ to $8.6 \%$; both spouses from $27.1 \%$ to $55.3 \%$; husband alone from $69.5 \%$ to $28.4 \%$ ), and whether she can visit family or friends (wife alone from $4.2 \%$ to $10.0 \%$; both spouses from $32.0 \%$ to $51.6 \%$; and husband alone from $63.8 \%$ to $25.2 \%$ ). Each of these changes was statistically significant.

Women also experienced statistically significant increases in mobility (i.e., being allowed to travel to places alone without a spouse or another escort). Participants reported experiences in being able to go to the market alone $(28.3 \%$ to $73.1 \%)$, a health facility alone $(23.3 \%$ to $62.1 \%)$, visiting friends or family within the village alone $(37.7 \%$ to $62.8 \%$ ), and visiting friends or family outside of the village alone (11.9\% to $40.1 \%)$.

Improvements were seen in all indicators related to attitudes and domestic violence (Table 5). Notably, the percentage of women who felt very confident that they could afford nutritious foods increased from $15.4 \%$ to $33.3 \%$ and the percentage of women who felt somewhat confident that they could afford nutrition foods increased from $38.7 \%$ to $52.8 \%$.

Additionally, the percentage of women who felt that a husband was justified in hitting his wife decreased from $20.1 \%$ to $2.2 \%$. Lastly, the percentage of women who were afraid of their husband most of the time decreased from $17.4 \%$ to $4.6 \%$, and those who were afraid of their husband some of the time decreased from $75.4 \%$ to $64.5 \%$.

\section{Discussion}

The purpose of this study was to evaluate whether the RNP led to changes in 1) dietary habits and nutrition, and 2) indicators of gender equality, female autonomy, and empowerment, including social norms, intra-household decision-making dynamics, female mobility, and domestic violence. Results of the present study indicate that the RNP is a potentially effective intervention. Dietary habits and nutrition improved between the baseline and endline assessments

Table 5. Attitudes and domestic violence.

\begin{tabular}{ccc}
\hline Variable & Baseline \% & Endline \% \\
\hline Feels very confident that she can afford nutritious foods & 15.4 & $33.3^{*}$ \\
Feels somewhat confident that she can afford nutritious foods & 38.7 & $52.8^{*}$ \\
Felt somewhat hopeful in the past year & 25.6 & $66.5^{*}$ \\
Feels very satisfied with the life she leads & 59.8 & $31.5^{*}$ \\
Feels somewhat satisfied with the life she leads & 9.7 & $28.6^{*}$ \\
Feels a husband is justified in hitting or beating his wife & 52.1 & $62.8^{*}$ \\
In the last 12 months, was afraid of husband/partner most of the time & 17.4 & $2.2^{*}$ \\
In the last 12 months, was afraid of husband/partner some of the & 75.4 & $64.5^{*}$ \\
time
\end{tabular}

${ }^{\star}$ Indicates statistically significant at $\mathrm{p}<0.05$. 
of the RNP, as did several indicators of gender equality, female autonomy, and empowerment.

Both the percentage of babies who were breastfed within one hour of birth and the percentage of babies who were exclusively breastfed for the first six months increased significantly over the course of the intervention. In addition, significant improvements to female autonomy and decision-making power were seen as a result of the RNP. While this study did not assess the direct relationship between female autonomy and breastfeeding outcomes, previous studies on breastfeeding in India suggest there is a relationship, which could explain the results of the present study. Benedict et al. [23] found that there was an association between low decision - making autonomy and suboptimal early initiation of breastfeeding in India and Pakistan. A review by Sharma \& Byrne [24] found that lack of mother's involvement in decision-making contributes to not initiating breastfeeding within one hour of birth. Bose [25] found that increases in women's autonomy were associated with increases in breastfeeding. Shroff et al. [26] found that maternal financial autonomy was significantly associated with exclusive breastfeeding among infants 3 - 5 months of age. In addition, a systematic review conducted by Carlson et al. [5] strongly suggested that improving women's autonomy is an essential step towards improving children's nutritional status. However, Rajaram et al. [27] found a statistically insignificant association between women's autonomy and child nutritional outcome.

Both the percentage of children and the percentage of mothers who were considered food secure improved significantly over the course of the intervention, suggesting the effectiveness of comprehensive, multi-faceted nutrition interventions similar to the RNP. The RNP included interventions to improve measures of both female empowerment and female nutritional knowledge. A review by Pandey et al. [28] suggests that female empowerment and nutrition knowledge are both crucial for improving nutritional outcomes in South Asia. Another review by Kumar et al. [29] concluded that women's groups that target multiple determinants of undernutrition, such as the SHG included in the RNP, are likely useful tools for nutrition change in South Asia. Other studies on the relationship between autonomy and the nutritional status of children have had mixed results. A systematic review conducted by Cunningham et al. [30] found that there was a general association between women's empowerment in the household and child nutritional status in South Asia; but, the authors noted that the mixed results seen in some studies could be due to differences in study settings, population characteristics, and methods used to measure women's empowerment. Despite study limitations, the results of a systematic review by Carlson et al. [5] strongly suggest a relationship between maternal autonomy and child nutritional status.

Significant improvements related to household decision-making, communication, and mobility were seen as a result of the RNP, suggesting that the RNP was generally successful at increasing female autonomy. In regards to household decision-making, there were statistically significant increases in whether or not a 
woman seeks health care for herself. These findings are consistent with the findings of previous studies. Lamichhane [31] found that women's decision-making autonomy regarding their own health care and control over earnings were significantly associated with maternal health care service utilization in Nepal. In addition, Adhikari [32] found that women's autonomy was significantly associated with use of maternal health care services in Nepal. Wado et al. [33] found that women's autonomy was significantly associated with use of contraception and use of antenatal care in Ethiopia. A systematic review conducted by Osamor et al. [34] demonstrated a link between women's autonomy and health care decision-making (e.g. use of general health care services, pregnancy care services, and contraception). Similar to the present study, researchers used various indicators, including household decision-making, control over finances, mobility, and freedom from violence, to measure women's autonomy.

Another aspect of household decision-making is control of finances, in relation to both general spending and specific spending on food. For both measures, the percentage of women making decisions related to finances either alone or in partnership with their husbands rose significantly as a result of the RNP, while the proportion of men making financial decisions alone decreased significantly. These findings could explain other results of the RNP, such as improvements to food security, of both the mothers and their children. A review by Taukobong et al. [6] found that female control over income, assets and/or resources was a significant predictor of the nutritional status of mothers and children; the majority of studies included in the review related to nutrition were based in South Asia. Another study by Rahman et al. [35] found that maternal household decision-making autonomy, including the ability to make household purchases independently or in partnership with another person (e.g., husband), was a predictor of child nutrition outcomes in Bangladesh. Chatterjee \& Dubey [9] also found that female financial autonomy was significantly associated with child nutrition outcomes, including stunting, in India. If a woman is allowed to purchase foods for her family on a daily basis, then she likely has fair amount of control over her children's diet and resource allocation, leading to better nutrition outcomes.

All indicators related to mobility improved significantly over the course of the intervention. As a result of the RNP, there was a significant increase in the percentage of women who reported that they could travel places alone (e.g., to market, to health facility, to visit friends of family within the village, or to visit friends or family outside of the village). This finding may also explain results of the RNP related to food security and nutrition. A review conducted by Taukobong et al. [6] found strong, positive relationships between mobility and several outcomes, including nutrition, family planning, and maternal, newborn, and child health. A study conducted in India by Shome et al. [36] found that maternal mobility and financial independence were significantly associated with infant birth weight. Anwar et al. [37] found that women's autonomy (as measured by 
freedom of movement, age at marriage, access to resources, communication with husband, and freedom from domestic violence) was related to their role in household decision making in Pakistan. After controlling for mother's education, Chatterjee \& Dubey [9] found that maternal mobility and financial independence were related to child nutrition. However, a study by Bhagowalia et al. [38] found that mobility did not directly improve child nutritional status. Despite this finding, the authors explain that mobility could be associated with other child outcomes that were not explored in the study.

Finally, improvements were seen in all indicators related to attitudes and domestic violence. The RNP resulted in a significant decrease in the percentage of women who were accepting of domestic violence, were afraid of their husband some of the time, or were afraid of their husband most of the time. These findings suggest that the RNP led to improvements in familial relations. This is important, as research has shown that there is a possible link between experiencing or condoning domestic violence and maternal and child nutrition outcomes. A study from a state in South India by Sethuraman et al. [39] found that a mothers' experience of violence disempowers them and undermines their own and their children's nutritional status. Another study by Bhagowalia et al. [38] found that a women's condoning of domestic violence increases the odds that her child is stunted. However, the review by Taukobong et al. [6] found mixed results on the impact of domestic violence on nutrition outcomes in South Asia. One explanation offered for a non-significant relationship is the normative nature of violence experienced and thus accepted by women in many parts of India.

\section{Limitations}

The authors acknowledge some of the challenges associated with an approach like the RNP, such as managing multiple program components simultaneously and ensuring the quality of all those components. While integrated approaches are gaining in popularity and the evidence is growing that demonstrates the importance of comprehensive poverty-alleviation programs, the provision of multi-pronged programs can result in certain components of the program taking longer to get started or being more limited in scope than other components. For example, male engagement in the RNP was much more limited than anticipated. In addition, all program components were not always implemented by the same people and therefore coordination of multiple efforts had to be carefully monitored to ensure the intensity and quality of implementation occurs as anticipated. This was accomplished through setting outcome targets prior to program implementation, which ensured the implementing teams stayed focused on improving prioritized outcomes of interest, such as outcomes in food security and improved breastfeeding rates. Future implementation of the RNP in other settings must consider these challenges.

Although this study is a robust observational study with a large sample size, the RNP lacked a comparison group, meaning that the effectiveness of the RNP 
intervention must be considered within this context. Given this, the changes measured in knowledge, behaviors, and attitudes cannot be interpreted as being caused by the RNP, but rather are only suggestive of the possible impacts a project like this could achieve. Future projects should consider randomizing participants to intervention and control groups to better assess the effectiveness of the RNP.

It is also important to note that the effectiveness of the gender component of the RNP cannot be fully attributed to the RNP due to the occurrence of other social norm change interventions occurring concurrently, such as village meetings where men were invited to learn from the SHGs and general engagement of the study communities around gender issues. Thus, the effectiveness of the gender component of this project is likely subject to factors beyond the RNP itself, such as the legacy of the SHG movement and additional community involvement in SHG activities.

The RNP only measured female autonomy and decision-making power from the women's perspective, which could lead to an over- or under-estimation of the actual agency she has. Prior research indicates that there is often a difference between the decisions women delegate to themselves or perceive their have control over and the decisions their husbands or society actually delegate to them [40]. Future research should include men in evaluations of female autonomy and intra-household decision-making to better understand changes in this area.

\section{Conclusions}

Despite the study's limitations, the changes that occurred between baseline and endline are promising and indicate that the RNP is an intervention that warrants further exploration. Dietary habits and nutrition improved between the baseline and endline assessments of the RNP, as did several indicators of gender equality, female autonomy, and empowerment. These results indicate that the RNP is a potentially effective intervention.

Further research on the association between female autonomy and nutrition outcomes, as a result of the RNP, may be warranted. While the RNP led to significant improvements in several indicators of nutrition and female autonomy, the present study did not assess the association between those indicators of nutrition and female autonomy. Additional research is needed to determine if improvements to nutrition stemmed from increased female autonomy, or if better nutrition outcomes occurred independently of autonomy variables. Additional research is also needed to determine if the RNP would be equally as effective in other regions of India, or even in populations outside of India.

Overall, the RNP is a promising intervention for improving nutrition and female autonomy in Rajasthan, India that should be considered for implementation in other communities in Rajasthan.

\section{Acknowledgements}

We would like to thank our partners, Professional Assistance for Development 
(PRADAN) and the Voluntary Association of Agricultural General Development Health (VAAGDHARA) for their contribution to this research. In addition, we express our appreciation to data collection team at the Institute of Health Management Research for conducting baseline and endline data collection. Finally, we would like to thank the Barr Family Foundation for funding this research.

\section{Conflicts of Interest}

The authors declare no conflicts of interest regarding the publication of this paper.

\section{References}

[1] Grebmer, K.V., Bernstein, J., Patterson, F., Wiemers, M., Chéilleachair, R.N., Foley, C., Gitter, S., Ekstrom, K. and Fritschel, H. (2019) 2019 Global Hunger Index: The Challenge of Hunger and Climate Change. Concern Worldwide, Dublin.

[2] Nuru, H. (2007) WFP India Brief. World Food Programme, Rome.

[3] Brody, A., Spieldoch, A. and Aboud, G. (2014) Gender and Food Security: Towards Gender-Just Food and Nutrition Security. Institute of Development Studies, Brighton.

[4] Harris-Fry, H., Shrestha, N., Costello, A. and Saville, N.M. (2017) Determinants of Intra-Household Food Allocation between Adults in South Asia-A Systematic Review. International Journal for Equity in Health, 16, Article No. 107. https://doi.org/10.1186/s12939-017-0603-1

[5] Carlson, G.J., Kordas, K. and Murray-Kolb, L.E. (2015) Associations between Women's Autonomy and Child Nutritional Status: A Review of the Literature. Maternal \& Child Nutrition, 11, 452-482. https://doi.org/10.1111/mcn.12113

[6] Taukobong, H.F.G., Kincaid, M.M., Levy, J.K., Bloom, S.S., Platt, J.L., Henry, S.K. and Darmstadt, G.L. (2016) Does Addressing Gender Inequalities and Empowering Women and Girls Improve Health and Development Programme Outcomes? Health Policy and Planning, 31, 1492-1514. https://doi.org/10.1093/heapol/czw074

[7] Ickes, S.B., Heymsfield, G.A., Wright, T.W. and Baguma, C. (2017) "Generally the Young Mom Suffers Much:" Socio-Cultural Influences of Maternal Capabilities and Nutrition Care in Uganda. Maternal \& Child Nutrition, 13, ee12365. https://doi.org/10.1111/mcn.12365

[8] Imai, K.S., Annim, S.K., Kulkarni, V.S. and Gaiha, R. (2014) Women's Empowerment and Prevalence of Stunted and Underweight Children in Rural India. World Development, 62, 88-105. https://doi.org/10.1016/j.worlddev.2014.05.001

[9] Chatterjee, P. and Dubey, A. (2018) The Role of Women's Empowerment on Child Nutrition in India. Centre for the Study of Regional Development, Jawaharlal Nehru University, New Delhi.

[10] Aguayo, V.M., Nair, R., Badgaiyan, N. and Krishna, V. (2016) Determinants of Stunting and Poor Linear Growth in Children under 2 Years of Age in India: An In-Depth Analysis of Maharashtra's Comprehensive Nutrition Survey. Maternal \& Child Nutrition, 12, 121-140. https://doi.org/10.1111/mcn.12259

[11] Shroff, M., Griffiths, P., Adair, L., Suchindran, C. and Bentley, M. (2009) Maternal Autonomy Is Inversely Related to Child Stunting in Andhra Pradesh, India. Maternal \& Child Nutrition, 5, 64-74. https://doi.org/10.1111/j.1740-8709.2008.00161.x

[12] Dev, S.M. and Sharma, A.N. (2010) Food Security in India: Performance, Chal- 
lenges and Policies. Oxfam India, New Delhi.

[13] World Bank (2016) Rajasthan-Poverty, Growth and Inequality (English). India State Briefs. World Bank Group, Washington DC.

[14] Raykar, N., Majumder, M., Laxminarayan, R. and Menon, P. (2015) India Health Report: Nutrition 2015. Public Health Foundation of India and International Food Policy Research Institute (IFPRI), New Delhi.

[15] International Institute for Population Studies (2017) State Fact Sheet: Rahasthan. International Institute for Population Studies, Mumbai.

[16] World Bank (2016) Rajasthan-Gender (English). India State Briefs. World Bank Group, Washington DC.

[17] Gray, B., Das, A., Chandler, C. and Rao, S. (2017) Nutrition at the Centre: Client Outcomes of the Rajasthan Nutrition Project. Grameen Foundation, Washington DC.

[18] Gray, B. and Kabra, M. (2016) Rajasthan Nutrition Project: Integrating Financial, Agricultural, Nutrition Services and Gender. Freedom from Hunger, Davis.

[19] Schreiner, M. (2016) Poverty Probability Index-India.

[20] Maxwell, D. and Caldwell, R. (2008) The Coping Strategies Index: Field Methods Manual. 2nd Edition, Feinstein International Center, Tufts University, Boston \& TANGO, Tuscon.

[21] Kennedy, G., Ballard, T. and Dop, M. (2011) Guidelines for Measuring Household and Individual Dietary Diversity. Food and Agriculture Organization of the United Nations, Rome.

[22] International Institute for Population Studies (2017) National Family Health Survey (NFHS-4). International Institute for Population Studies, Mumbai.

[23] Benedict, R.K., Craig, H.C., Torlesse, H. and Stoltzfus, R.J. (2018) Trends and Predictors of Optimal Breastfeeding among Children 0-23 Months, South Asia: Analysis of National Survey Data. Maternal \& Child Nutrition, 14, e12698. https://doi.org/10.1111/mcn.12698

[24] Sharma, I.K. and Byrne, A. (2016) Early Initiation of Breastfeeding: A Systematic Literature Review of Factors and Barriers in South Asia. International Breastfeeding Journal, 11, Article No. 17. https://doi.org/10.1186/s13006-016-0076-7

[25] Bose, S. (2011) The Effect of Women's Status and Community on the Gender Differential in Children's Nutrition in India. Journal of Biosocial Science, 43, 513-533. https://doi.org/10.1017/S002193201100006X

[26] Shroff, M.R., Griffiths, P.L., Suchindran, C., Nagalla, B., Vazir, S. and Bentley, M.E. (2011) Does Maternal Autonomy Influence Feeding Practices and Infant Growth in Rural India? Social Science \& Medicine, 73, 447-455. https://doi.org/10.1016/j.socscimed.2011.05.040

[27] Rajaram, R., Perkins, J.M., Joe, W. and Subramanian, S.V. (2017) Individual and Community Levels of Maternal Autonomy and Child Undernutrition in India. International Journal of Public Health, 62, 327-335.

https://doi.org/10.1007/s00038-016-0850-8

[28] Pandey, V. L., Mahendra Dev, S. and Jayachandran, U. (2016) Impact of Agricultural Interventions on the Nutritional Status in South Asia: A Review. Food Policy, 62, 28-40. https://doi.org/10.1016/j.foodpol.2016.05.002

[29] Kumar, N., Scott, S., Menon, P., Kannan, S., Cunningham, K., Tyagi, P., Wable, G., Raghunathan, K. and Quisumbing, A. (2018) Pathways from Women's Group-Based 
Programs to Nutrition Change in South Asia: A Conceptual Framework and Literature Review. Global Food Security, 17, 172-185.

https://doi.org/10.1016/j.gfs.2017.11.002

[30] Cunningham, K., Ruel, M., Ferguson, E. and Uauy, R. (2015) Women's Empowerment and Child Nutritional Status in South Asia: A Synthesis of the Literature. Maternal \& Child Nutrition, 11, 1-19. https://doi.org/10.1111/mcn.12125

[31] Lamichhane, K. (2018) Women's Autonomy and Utilization of Maternal Health Care Services in Rural Nepal. Nepal Population Journal, 18, 73-80. https://doi.org/10.3126/npj.v18i17.26379

[32] Adhikari, R. (2016) Effect of Women's Autonomy on Maternal Health Service Utilization in Nepal: A Cross Sectional Study. BMC Women's Health, 16, Article No. 26. https://doi.org/10.1186/s12905-016-0305-7

[33] Wado, Y.D. (2018) Women's Autonomy and Reproductive Health-Care-Seeking Behavior in Ethiopia. Women \& Health, 58, 729-743. https://doi.org/10.1080/03630242.2017.1353573

[34] Osamor, P.E. and Grady, C. (2016) Women's Autonomy in Health Care Decision-Making in Developing Countries: A Synthesis of the Literature. International Journal of Women's Health, 8, 191-202. https://doi.org/10.2147/IJWH.S105483

[35] Rahman, M.M., Saima, U. and Goni, M.A. (2015) Impact of Maternal Household Decision-Making Autonomy on Child Nutritional Status in Bangladesh. Asia-Pacific Journal of Public Health, 27, 509-520. https://doi.org/10.1177\%2F1010539514568710

[36] Shome, S., Pal, M. and Bharati, P. (2018) Influence of Maternal Autonomy and Socioeconomic Factors on Birth Weight of Infants in India. Malaysian Journal of $\mathrm{Nu}$ trition, 24, 35-46.

[37] Anwar, B., Shoaib, M. and Javed, S. (2013) Women's Autonomy and Their Role in Decision Making at Household Level: A Case of Rural Sialkot, Pakistan. World Applied Sciences Journal, 23, 129-136.

[38] Bhagowalia, P., Menon, P., Quisumbing, A. and Soundararajan, V. (2012) What Dimensions of Women's Empowerment Matter Most for Child Nutrition? Evidence Using Nationally Representative Data from Bangladesh. International Food Policy Research Institute, Washington, DC.

[39] Sethuraman, K., Lansdown, R. and Sullivan, K. (2006) Women's Empowerment and Domestic Violence: The Role of Sociocultural Determinants in Maternal and Child Undernutrition in Tribal and Rural Communities in South India. Food and Nutrition Bulletin, 27, 128-143. https://doi.org/10.1177\%2F156482650602700204

[40] Anderson, C.L., Reynolds, T.W. and Gugerty, M.K. (2017) Husband and Wife Perspectives on Farm Household Decision-Making Authority and Evidence on Intra-Household Accord in Rural Tanzania. World Development, 90, 169-183.

https://doi.org/10.1016/j.worlddev.2016.09.005 